\title{
A RADICAL COLLABORATIVE APPROACH: DEVELOPING A MODEL FOR LEARNING THEORY, HUMAN-BASED COMPUTATION AND PARTICIPANT MOTIVATION IN A ROCK-ART HERITAGE APPLICATION
}

\author{
R. Haubt ${ }^{\mathrm{a}}$ \\ ${ }^{a}$ PERAHU, School of Humanities, Griffith University, 4222 Southport, Australia - robert.haubt@griffithuni.edu.au
}

Commission V, WG V/2

KEY WORDS: rock art, cultural heritage, collaboration, human-based computation, crowd sourcing

\begin{abstract}
:
This paper explores a Radical Collaborative Approach in the global and centralized Rock-Art Database project to find new ways to look at rock-art by making information more accessible and more visible through public contributions. It looks at rock-art through the Key Performance Indicator (KPI), identified with the latest Australian State of the Environment Reports to help develop a better understanding of rock-art within a broader Cultural and Indigenous Heritage context. Using a practice-led approach the project develops a conceptual collaborative model that is deployed within the RADB Management System. Exploring learning theory, human-based computation and participant motivation the paper develops a procedure for deploying collaborative functions within the interface design of the RADB Management System. The paper presents the results of the collaborative model implementation and discusses considerations for the next iteration of the RADB Universe within an Agile Development Approach.
\end{abstract}

\section{INTRODUCTION}

The Rock-Art Database (RADB) is a heritage project at the Place, Evolution and Rock-Art Heritage Unit (PERAHU), Griffith University. The RADB aims to build a centralised global distribution system (GDS) type hub and repository for rock-art scholars and enthusiasts. This paper places Australian rock-art in an interdisciplinary and international heritage context and looks at how public contributions can assist with content collection and information collection for the development of the RADB Management Systems.

\section{REVIEW OF COLLABORATIVE APPLICATIONS}

The following section provides a review of collaborative approaches within Web, heritage and rock-art applications. The review informs a conceptual model and the implementation of a collaborative approach in the Rock-Art Database (RADB) project. To develop a basic understanding of the usefulness of collaborative approaches the project asks five questions:

- How are collaborative approaches used?

- What type of approaches exist?

- How can collaborative approaches help generate meaningful data?

- How can we motivate participants to engage in collaborations?

- What can we learn from the success and failure of existing collaborative projects?

\subsection{Collaborative Web Application Observations}

When we think about collaborative approaches on the Web, Open Source applications come to mind. Platforms such as GitHub, Drupal or WordPress allow developers to build applications with the help of an online community by controlling, managing and sharing conceptual ideas and code.
GitHub currently boasts over 11 million users and hosts over 29 million repositories making it the largest host for source code on the Web (Gousios et al., 2014). The platform offers contributions for all kinds of projects while other platforms like Drupal and Wordpress focus on development for their own frameworks. The Drupal network currently has over 30,000 contributors who have developed over 30,000 modules for over 1 million Drupal users (W3Techs, 2015). Technical contributions are even higher within Wordpress, where over 39,000 plugins have been developed and are deployed in over 72 million websites, making it the most used platform on the Web (Breslin et al., 2006).

But besides online communities for developers, collaborative approaches have also been used in content creation for Wikipedia, Reddit or Digg. Each application makes use of different kinds of participant contributions and includes collaborative writing of formalized articles, informed discussion forums and using humans to help with filter vast amounts of information on the Web.

Wikipedia is the world's largest online encyclopedia and is accessed every day by over 439 million people from across the globe. The platform currently features over 34 million articles ( 5 million in the English language) that have been added and edited by over 73,000 contributors. Wikipedia makes use of a markup format allowing users to add, edit and evaluate information while complying with a formalized form for article contribution entry.

Reddit on the other hand does not feature articles but instead offers the public to contribute to forum discussions on various topics. In Reddit, contributors can interact with each other and get informed by asking questions, answering questions or sharing ideas by joining discussions. According to the official Reddit website the platform has over 202 million visitors per month with more than 850,000 topic entries (called subreddits) added by over 36 million registered users. 
With an abundance of information available on the Web, it is becoming increasingly difficult to make sense of things. Digg is looking into the organization of information and has taken a completely different approach by using the power of the masses to filter out popular news and articles. The platform allows users to "digg" articles on the Web and if an article has enough "diggs" it is promoted to the websites homepage generating and identifying trends.

Another kind of collaborative social platform has emerged in the last few years and is attracting the attention of professionals and scholars by allowing showcasing online portfolios. Websites such as LinkedIn (launched in 2003), Academia.edu (launched in 2008) and ResearchGate (launched in 2008) offer users the opportunity to promote their profiles and their work with the ability to discuss and share information within a network of colleagues and likeminded participants. According to their own websites as of December 2015, LinkedIn has over 400 million, Academia.edu over 27 million and ResearchGate over 8 million users. While Academia.edu officially lists over 7 million uploaded research papers, ResearchGate does not provide an official number but a quick internal system search for all papers, lists just over 2.5 million texts.

To identify how collaboration was used within these projects we will place our findings into 5 basic categories. GitHub, Drupal and Wordpress use collaborations to develop conceptual and deployed technology online, while Wikipedia and Reddit look into collecting knowledge and ideas. Wikipedia takes a more formalized approach by providing templates to format and present articles while Reddit's discussion forums are often raw and unfiltered and are rather informed than formalized. Digg, LinkedIn, Academia and ReseachGate all help to filter data by different means. While Digg encourages users to highlight articles to discover current news trends, LinkedIn, Academia and ResearchGate filter out professionals and their work by creating a community of likeminded users within a social network type platform. We could place our findings so far into the following categories:

- Development of Technology

- Information Collection through articles (formalized)

- Information Collection through discussions (informed)

- Filtering information through likes, tags ("diggs")

- Filtering information through social groups

\subsection{Collaborative Heritage Application Observations}

Similar collaborative approaches exist in the development of heritage applications and collection and filtering of heritage data.

A number of conceptual and practical models for the implementation of cultural heritage reference models are currently shared on GitHub. These models are developed through projects such as X3ML Engine, Karma or Linked Ancient World Data (LAWD) and are monitored and forked (linking in GitHub) by up to 20 participants. While these projects are currently fairly limited in the number of contributions, they do provide an important interdisciplinary approach towards conceptualizing data sharing in international heritage data models towards a Semantic Web and inform projects such as the CIDOC CRM task group at ICOMOS (ICOM/CIDOC Document Standards Group, CIDOC CRM Special Interest Group, 2015).
A much larger heritage project is being developed using the Open Source platform, Drupal. Mukurtu is a Content Management System (CMS) initially developed by a small team of researchers for a heritage project in Australia. Since its initial development, Murkurtu has been shared and improved by the Drupal community and is now used in over 1200 heritage management systems across the globe (Christen, 2013). Mukurtu embraces the Open Source community and has been further extended to incorporate Creative Commons and other legal services for its system design. The use of Drupal modules for the CMS and integration of Creative Commons makes Murkurtu one of the most versatile Open Source heritage projects on the Web.

While Murkurtu uses the public to help develop concepts and technology within Open Source communities, other projects such as Europeana, the Norwegian University of Life Sciences or the Power House Museum in Sydney, look at information collection through public contributions.

Europeana was launched in 2008 and functions as a centralized European meta-aggregator and display space for digitized heritage items. The project is supported by over 2,000 institutions from across Europe and currently features a collection of over 36 million heritage items. Europeana recently launched a new campaign called LoCloud. LoCloud is a crowdsourcing application that allows the public to contribute data to Europeana using a virtual account in the cloud. The idea behind the system is to engage the public in contributing hidden information, locked up in private archives at home, to expand Europe's heritage collection and help inform research through new contributions from the public (Gavrilis et al. 2015).

Similar to Europeana's LoCloud, Stuedahl \& Smordal experiment with engaging the public with Cultural Heritage through the Web (2012). At the Norwegian University of Life Sciences they explore the use of an online blog and YouTube to inform the reconstruction of an ancient boat. The experiment experienced large contributions from scholars and professional including carpenters and enthusiasts. Through public collaboration the project was able to retrieve ancient building methods that allowed for a better understanding of the heritage object.

Similar experiments have been conducted using Instagram and flickr to expand and inform heritage collections. Flickr was used at the Power House Museum in Sydney to assist with a collection of photographs, allowing the public to tag and link images (Bak, 2012; Weilenmann, 2013).

Collaborative approaches are used in heritage applications to develop conceptual models or develop new platforms such as Murkurtu. Heritage collections, at Europeana or the Power House Museum, expand through public contributions and integrate popular platforms such as flickr or Instagram to assist with the collaborative process. But public contributions can also inform research and research method as presented by Stuedahl \& Smordal.

At the Museum of Modern Art (MOMA) such collaborative and interdisciplinary approaches have been recognized and implemented in the design of the new museum's database management system (Raiciulescu, 2012). The system brings together interdisciplinary departments to share knowledge and improve communication across different fields. 
Few results have been published to date by MOMA on the new interdisciplinary system but the previous examples illustrate how working together can help with a range of data collection and research tasks and improve our understanding of the world.

\subsection{Collaborative Australian Cultural and Indigenous Heritage Application Observations}

Looking at the national and state based Australian heritage bodies such collaborative approaches seem to be missing. More than 49 heritage bodies have deployed over 49 websites in a highly decentralized system but no collaborative structure between these systems can be found.

The State of the Environment Report looks at a set of Key Performance Indicator (KPI) to assess the state of heritage in Australia. The last report revealed a gap in identifying, managing, protecting, leadership and celebrating Cultural Heritage and in particular Indigenous Heritage and sections of the report are even left blank (Department of the Environment, 2011). The report links these gaps to a lack of available information to the departments. How can 49 heritage bodies not have enough information? Two possible options come to mind:

a) Information sharing between agencies is inefficient

b) Data acquisition by agencies is inadequate for the subject matter

Both options have been addressed within the State of the Environment Report with no proposed solution to date.

\subsection{Collaborative Rock-Art Application Observations}

Rock-Art research is highly interdisciplinary and collaborative, bringing together researchers from social sciences and the arts with the natural sciences. While social sciences and arts researchers investigate, for example, the origins of art and Human Diaspora, researchers in the natural sciences support findings through empirical research in, for example, biological sampling or carbon dating.

Even though rock-art is an interdisciplinary and collaborative field of research, it is difficult to find information about collaborative work on the Web besides information published in academic papers. Much data is locked away in decentralized, access restricted or private archives.

The biggest collaboration within the specialized field is arguably achieved through the International Federation of RockArt Organizations (IFRAO) and the Australian Rock-Art Association (AURA). Both organizations arrange frequent conferences bringing together hundreds of scholars and enthusiasts from around the world. Even though the organizations help to bring people together in person, no online system has been implemented to help form a virtual online community for rock-art as seen at MOMA, Europeana, Wikipedia or Reddit.

Instead, rock-art is often discussed in hard to find smaller forums such as private blogs or within social networks such as Facebook, LinkedIn, Academia.edu or ResearchGate. Groups such as the Students of World Rock Art on LinkedIn, with 31 participants, are hidden away and only show little contributions to the greater community with entries only occurring every few months.
Tagging and following functions in Academia, however, seem to reach larger audiences. As of December 2015 the tag "Rock Art (Archaeology)" has 8345 followers, "Rock Art" has 4260 followers, "Prehistoric Rock Art" has 2826 followers and "Rock Art research" has 368 followers. Even though tagging and following allows users to filter through the available content, the inconsistent use of the term rock art causes problems finding targeted information. It is interesting to note that the keyword "rock art" itself has less followers than "rock art (Archaeology)". This might be a reflection of messy categories in Acaedmia.edu and shows how users try to eliminate confusion with the use of the term, by adding more defining attributes.

ResearchGate also allows tagging and following key words. "Rock Art" in ResearchGate has 500 followers, 1 discussion forum with 12 entries (84 entry followers), 200 posted questions and over 4,400 papers. But a closer look at individual papers reveals that many have little to no actual connection to rock art research but rather make use of the term in some other context. No additional attributes, as seen in Academia.edu, are used in ReseachGate to further filter this data.

It is interesting to note that considering rock-art research methods, such as Formal \& Informed Methods discussed by Chippindale \& Taçon (1998), collaborative approaches such as witnessed in Wikipedia, Reddit or Digg, have not been greatly explored within the specialized field (1998). Formalizing articles through public collaboration or informing the public through discussions forums, both show potential in exploring competing ideas in Scientific Method or the collection of ethnographic data through user comments, tags and links.

\subsection{Observation Summary}

Little collaborative online networks within rock-art have been found since the start of this research project in 2012. This paper proposes to investigate the use of collaborative approaches in all levels of system design, from developing conceptual models and technology to content collection, management and data dissemination. Looking at the specialized field of rock-art within an Australian Heritage context, the model should consider Formal \& Informed Methods for rock-art research and address the Australian Cultural and Indigenous Heritage KPI.

\section{DEVELOPING A METHODOLOGY}

\subsection{Needs, Aims \& Outcomes}

The project proposes to investigate the use of Collaborative Approaches in theory and practice within the RADB project to help address gaps within Australian Cultural and Indigenous Heritage Management and rock-art. The Collaborative Approach aims to address the Australian Cultural and Indigenous Heritage KPI and Formal \& Informed Methods for rock-art research to explore new ways for looking at rock-art by making information more accessible and more visible. The RADB project addresses four key questions regarding the usefulness of a Collaborative Approach:

I. How can a Collaborative Approach assist with finding new ways to look at rock-art information by making information more accessible and more visible?

II. How can a Collaborative Approach address the Australian Cultural and Indigenous Heritage KPI (Department of the Environment, 2015). 
III. How can a Collaborative Approach help with Formal \& Informed Methods in rock-art (Chippindale \& Taçon, 1998)?

IV. How can the Radical Collaborative Approach be used in theory and practice in the $R A D B$ Universe.

\subsection{A Collaborative Approach within the RADB Universe}

To address these aims the project develops an approach by drawing from the findings in the previous section and explores them in more details within three categories:

I. Building a Community of Participants (Organization)

II. Exploring Functions of Collaborative Approaches (Conceptual Model)

III. Developing Tools in Support of Collaborative Approaches (Deployed Model)

These three categories are reflected within the RADB Universe. The RADB Universe describes the entire RADB project on multiple levels, where each level generates different outputs. The Universe is based on the DL model and can be broken down into three interrelated tiers (European Commission Information Society and Media, 2011):

Tier 1: RADB (as an organization)

Tier 2: RADB System (conceptual model)

Tier 3: RADB Management System (the deployed model)

To contextualize the three categories in the RADB Universe tiers, the project considers a Radical Collaborative Approach, envisioning how all aspects of system design and application usage can be collaborative. Further, the research looks at how meaningful data can be generated, through considering the use of Learning Theory that could help with educating visitors but also improve user contributions towards creating new knowledge. To develop a better understanding of the role of people within the system, the research explores functions in Human-Based Computation and how motivation of participants can help build a community of users. The last step brings together the $R A D B$ Universe, the Radical Collaborative Approach, Learning Theory, Human-Based Computation and Participant Motivation by looking at the conceptual and deployed Interface Design and implemented procedures.

3.2.1 A Radical Collaborative Approach: Swartz has identified collaboration on the Web as a vital factor to contributions to knowledge and proposes to explore new systems through a Radical Collaborative Approach (2006). The idea is to explore all elements of applications, including system design and system usage through contributions from the public, based on the Wikipedia experience. His model is moving away from traditional organizational structures, allowing contributions from whomever, wherever and whenever. Swartz proposes to focus on exploring new Radical Collaborative system designs rather than deploying more platforms. To develop such new approaches he makes the following statement and asks 5 questions:

"We don't need more system installations but rather a system that supports such a collaborative approach!'’(Swartz, 2006)

- What is data good for?

- What rules apply?

- How can we bring data together?

- How can we make sense of it all?

- What kind of application should we use?
To contextualize Swartz's questions with our previous findings, the project proposes to explore 4 key aspects within a Radical Collaborative Approach:

- Generating Knowledge: How can we generate knowledge through a Radical Collaborative Approach to explore what data is good for?

- Conceptual Model: What functions and rules can we apply to a Radical Collaborative Approach to help bring data together and allow us to filter and make sense of it all?

- Deployed Tools: What technical functions support a Radical Collaborative Approach?

- Participant Motivation: How can we motivate the public to participate and bring information together in one centralized system?

3.2.2 Generating Meaningful Data Through Learning Theory: "To promote higher-order thinking on the Web, online learning must create challenging activities that enable learners to link new information to old, acquire meaningful knowledge, and use their metacognitive abilities; hence, it is the instructional strategy and not the technology that influences the quality of learning." (Bonk \& Reynolds, 1997)

In order to support participants and create more meaningful data, the research proposes to include learning theory within the Radical Collaborative Approach. Similar to Swartz, Bonk \& Reynolds (1997) propose that it is not the technology but the strategy that influences the quality of the outcome. The implementation of learning theory could assist with participant collaboration for a specific problem and help with the collection of meaningful information and generating knowledge (Gafni \& Geri, 2010; Du et al., 2007).

Constructivist Theory and Constructionist Theory support such collaborative learning approaches in online environments (Alzaghoul, 2013; Bruckman, 2004). Constructivist Learning argues that knowledge and meaning is generated through the interaction between experience and ideas (Roschelle, 1992; Piaget, 1967; Pack \& Goicoechea, 2000). Recent work on Communal Constructivism in the European School Net Project showed how students can construct knowledge in peer to peer learning environments without the classic social construct of learner and teacher learning (Leask \& Younie, 2001; Wood, 1998; Tangney et al., 2001; Girvan \& Savage, 2010).

Constructionist Theory further supports the idea of Constructivist Learning through collaborative approaches but takes it a step further and argues that learning is most effective if learning is experienced through the construction of a meaningful product (Sabelli, 2008; Papert \& Harel, 1991). An online system must facilitate communal learning experiences that produce meaningful outputs for the participants to be motivated to engage in generating knowledge.

This type of learning not only supports the idea of developing knowledge through, for example, informed approaches such as discussion forums in Reddit, or through formalized collective editing such as in Wikipedia, but also shows the importance of leaving the learner with a sense of having an impact through their contribution (Forte \& Bruckman, 2007; Yueh et al. 2015).

If we combine the idea of collaborative knowledge generation through Communal Constructivism and Constructionist Learning Theory in collaborative approaches, we could find use for Scientific Method of competing ideas and the Informed Methods for rock-art research (Chippindale \& Taçon, 1998). 
Ethnographic data can be collected through public contributions in informed discussion forums while competing ideas can be explored through discussion and deployed formalized empirical models.

The research looks at Constructivist and Constructionist Theory within a Radical Collaborative Approach to generate meaningful data and knowledge within Formal \& Informed Methods addressing the Australian Cultural and Indigenous Heritage KPI.

3.2.3 Human-Based Computation: Having established a learning theory approach to generate meaningful data and knowledge, and not just more data, the next question is what type of functions we can use within a Radical Collaborative Approach. As explored within Web, heritage and rock-art applications, we can find 3 ways of how humans can help with computational tasks to make more sense of data on the Web.

i) Crawler

One of the biggest problems is finding data in the Deep Web, which is addressed in Digg. The Deep Web describes data that is not as visible as other data on the Web, predominantly websites that are whether not listed in search engine results or are so far down the list that we cannot easily find them. A common use of human-based computation is for people to function as a crawler. Rather than search engines doing the work, people can tag or link back to data in the Deep Web in a much more informed way, bringing hidden data to the surface (Khattab et al., 2009).

\section{ii) Filtering}

A second way to use human-based computation is through allowing people to evaluate available data and selecting the fittest contributions to promote within a ranked list. This type of human-based computation is often called Collaborative Filtering and is explored in platforms such as Digg but also LinkedIn, Academia.edu or ResearchGate, where users promote and filter papers, projects or user profiles.

iii) Add, Edit and Evaluate

The last type of human-based computation addressed in this project, is modelled on the Wiki experience. Wikis allow users to contribute to projects through adding and editing its content but also include version control, allowing to evaluate edits and revert back to previous versions of an entry (Cunningham \& Leuf, 2001). This is described in three basic functions:

- Add Content

- Edit Content

- Evaluate / Filter Content

3.2.4 Participant Motivation: "If instructional strategies are not grounded in an understanding of how learning occurs, they are unproductive and do little to affect learner persistence" (Bonk \& Reynolds, 1997)

As discussed by Bonk \& Reynolds (1997) and reflected in Constructionist Learning, participants are driven by meaningful outcomes. But what exactly constitutes a meaningful outcome and motivates users to participate? Development platforms such as GitHub or Wordpress might have a more practical use for participants as they generate tangible output in forms of conceptual models or code. Money is seldom exchanged for contributions and instead users reciprocate by sharing their own work in exchange for help. A similar effect can be seen in Academia or ResearchGate where users might upload and share papers in direct or indirect exchange for accessing other people's work. The platform further allows users to build a reputation by showcasing their profiles or uploaded data and in turn receive endorsements by other users for their contributions. Wightman (2010) looks into motivation in crowdsourcing and human-based computational tasks and defines four categories within two factors and two types of user motivation. The categories are (a) direct and competitive, (b) direct and noncompetitive, (c) indirect and competitive and (d) indirect and non-competitive. Building on Wightman's categories our observations and results can presented as follows:

\author{
Direct and Competitive \\ Receiving a share of the result \\ Build and increase online recognition and reputation \\ Indirect and Competitive \\ Reciprocity \\ Desire to test ideas and innovations \\ Desire to impact the system \\ Entertainment in Competitive Gaming Environment \\ Direct and Non-Competitive \\ Curiosity \\ Volunteer to support a cause \\ Desire to share knowledge \\ Fun \\ Indirect and Non-Competitive \\ Entertainment in Communal Gaming Environment
}

\subsection{Practice-Led Research Within An Agile Development Approach Using PIMRI Cycle}

The research in this project uses a practice-led approach to develop a conceptual and deployed model for implementing a Radical Collaborative Approach in the RADB project. The approach follows an Agile Development Cycle rather than a linear approach. The Agile Approach allows for revisitong findings and making changes to the conceptual and the deployed model within each iteration of the cycle.

The practice-led research follows PIMRI (plan, implement, monitor, review, improve) for quality assurance purposes and helps to inform the investigator in the role of the researcher (conceptual) and the practitioner (deployed) within the Agile Development Approach.

The following section breaks down the conceptual mapping process, the deployed functions and outlines the procedures within the practice-led research approach using an Agile Development Approach and PIMRI cycle.

3.3.1 Conceptual Model Mapping: The Radical Collaborative Approach is mapped against the Australian Cultural and Indigenous Heritage KPI and rock-art research methods to explore new ways to make rock-art more accessible and more visible. The mapped model addresses all three tiers with the RADB Universe including (a) the $R A D B$ as an organization and the role of people, (b) the RADB System as a conceptual model and (c) the RADB Management System with its deployed functions.

i) The Australian Cultural and Indigenous Heritage KPI identified within the State of the Environment Report (Department of the Environment, 2011):
-Identify
- Manage
- Protect
- Leadership
- Celebrate 
ii) Rock-Art Research Methods (Chippindale \& Taçon, 1998)

- Formal Methods

- Informed Methods

iii) A Radical Collaborative Approach (Swartz, 2006)

- Learning Theory and Virtual Environments

-Human-Based Computation

- Participant Motivation

3.3.2 Deployed Model Mapping: The interface design now needs to bring together the learning theory (cognition), humanbased computation and participant motivation elements (Rahmanian \& Davis, 2013). The interface needs to allow people to contribute to the organization, conceptual and practical development as well as generate content for the $R A D B$ Collection. The design maps the Radical Collaborative Approach against areas for contributions and technical functions in the deployed RADB Management System.

i) Radical Collaborative Approach

-Learning Theory

- Human-Based Computation

- Participant Motivation

ii) Areas Available for Contributions within the RADB

Universe (in WordPress, GitHub and RADB Wiki)

Conceptual Development

-Thesaurus

- Reference Model and ontology

Practical Development

- Code (html, html5, x3dom, javascript, php,

MySQL, XML, RDF, SKOS etc.)

iii) RADB Content (in RADB Management System) Collection, News, Projects, Places, Sites, Items, Library (references, publications and conferences), User Profile

iv) Deployed Functions in Content Management System Hyperlinks $<$ href $>$, Links $<$ link $>$, Social Media Sharing <metadata OG:>, Discussion Forums, Feed Summary, Email Alert, Comment Sections, RSS, RDF, XML, OG, Tweed, Follow, Likes, Tagging
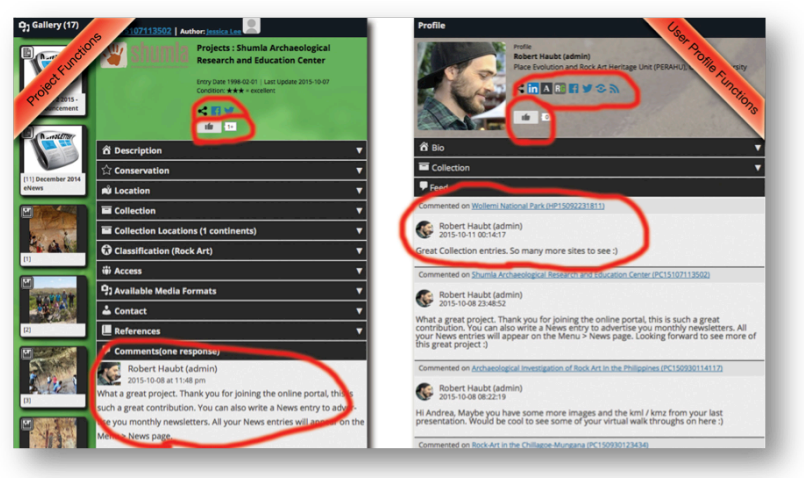

Figure 1: Collaborative Functions: Project (left) and User Profile (right) include Feed, Follow, RSS, Like, Comment, Thread, Linking and Social Network Functions

\section{PRESENTATION AND DISCUSSION OF RESULTS}

\subsection{Visitors, Participants and Content Contributions}

The Rock-Art Database Management System has attracted over 4000 visitors since its launch in 2014 and numbers have increased since full user registration was made available in July 2015. The platform has experienced over 11,000 page views with an average session duration of $2 \mathrm{~min}$ and 39 seconds. The number of returning visitors has been fairly steady since the initial launch at $23.9 \%$. Considering the niche this website presents the project has so far been successful in bringing people together to experience and share rock-art data.

In July 2015 the platform was made available for full contributions from scholars and enthusiasts through a user registration process. Since opening for registration, 12 users from 4 continents have signed up for accounts. The users to date include 10 heritage scholars within anthropology and archaeology, 1 information technology expert and 1 rock-art enthusiast. While the new users frequently engage with the site, content contributions have been slow with 10 projects $(5$ public and 5 private) uploaded to date. Out of the 5 public projects 2 have experienced extensive use. SHUMLA, a rock-art project in the USA and PERAHU, a rock-art project at Griffith University (where the RADB project originates) have used the platform to upload Projects, Places and Site information in text and multi media formats. In total 12 newsletters, over 100 images and 10 videos have been contributed since July 2015.

\subsection{Implemented Functions}

The RADB Management System implemented discussion forums, comment sections, likes, RSS feeds, follow and sharing functions. A summary of all user interaction is presented on the User Profile page. While most of the functions have only experienced limited use to date User Profile views have had the most engagement with up to 63 visits per profile since July 2015 (5 months). Comments, likes and follow functions have experienced insufficient use to date and as a result participant motivation will need to be re-evaluated in the next Agile Development iteration.

\subsection{Development Contributions}

Contributions and feedback for the conceptual model development (RADB System) have been plenty within 5 conference and 2 publications over the last 3 years. While most feedback came in responds to conference presentations, frequent exchange via email has been established with 3 Open Source heritage organizations in South Africa, North America and Australia, mainly regarding information structure and linked data.

Further, papers and video presentations on the RADB project have been uploaded to LinkedIn, Academia.edu and ResearchGate and were linked back to the RADB project website. Two papers and 5 talks have been downloaded 149 times, and 2 video presentations have been downloaded 77 times. Following a video presentation at the Society for American Archaeology (SAA) conference in San Francisco in 2015, the RADB project was presented as a model for data centralization at the Arizona State Museum. The RADB has further been promoted through social media in various rock-art blogs, Facebook forums, LinkedIn forums, ResearchGate and Academia.edu. 
The development of the RADB Management System has experienced frequent contributions from the GitHub and WordPress community. Thirty-one plugins by 31 developers have been implemented with special GIS support from 2 WordPress developers. The special support came in exchange for contributions from the RADB developer to the GIS plugin and has been continues. Special support also came from 3 GitHub developers working on X3DOM with no request for reciprocation but pure interest in supporting the RADB. One developer within WordPress and GitHub provided special allround support for the RADB Management System, contributing code in php and javascript in exchange for being mentioned on the Credits site.

Altogether the RADB project has experienced more contributions to date from IT professionals and enthusiasts than from the rock-art or academic community. It is unclear why this is the case but it might be linked to multiple factors including the use of existing platforms such as GitHub and WordPress in favour of the IT community but also data sensitivity, trust in unknown online software, copyright issues (was addressed by one inquiry), suitability of the platform or esthetical presentation of the platform within the heritage community.

\subsection{General Issues}

While collaborative contributions in GitHub and WordPress were monitored since 2013, contributions with the RADB Management System were only made available in July 2015 and therefore only limited data could be collected within the last 5 months.

Most qualitative data was collected through email inquires from rock-art and heritage scholars. Most inquirers mentioned their interest in the project and the desire to contribute but addressed concerns regarding copyright, ownership over information and sensitive data including secret, sacred or politically delicate data.

Other feedback, mainly from IT professionals, addressed concerns about competition that this project could generate. An IT company in Australia proposed that the RADB project should purely focus on building a GDS hub rather than offering a GDS hub with repository functionalities. While the entire community could benefit from the GDS hub function, a repository would create direct competition for IT companies in heritage and archaeology. It was proposed that repositories should be left to IT professionals rather than the Open Source community as they have the means to guarantee high quality security standards as well as specialized technology skills to satisfy researchers special technical requests.

Another issue within the RADB project has been spamming and filtering out valuable from useless information. Over the last 5 months the site experienced over 100 comment entries seemingly related to rock-art content but actually advertising other unrelated services on the Web. After 5 months of allowing open comments the RADB now has limited comments to registered users to avoid this issue.

\section{CONCLUSION}

A Radical Collaborative Approach has been implemented in the $R A D B$ Universe and assisted within the development of the platform through means of Open Source forums such as GitHub and WordPress. Collaborative contributions within the rock-art community have been slow but steady. Considering the niche of the field of rock-art and that no major advertising campaign for the system was used, results have been satisfactory.

The theoretical model has demonstrated a collaborative approach for addressing Scientific Method, Formal \& Informed Methods in rock-art research under the Australian Cultural \& Indigenous Heritage KPI. While the theoretical model within a formal data collection approach such as $A d d$, Edit and Evaluate and an informed approach through discussion forums and human-based filtering, shows potential for identifying, managing and protecting heritage, a practical implementation needs further testing as results to date are insufficient for any preliminary conclusions.

While all KPI have been addressed within the conceptual model, the RADB Management System has provided leadership and celebrated rock-art heritage through engaging more than 4000 visitors and attracting 12 registered scholars from 4 different continents to participate in the project. The game approach for participant motivation should be further explored to encourage more global contributions, allowing users to benefit from the system through building their reputation and online recognition within the User Profile and RADB Collection.

To engage more visitors and to attract more users to register, the project proposes to roll out a global advertising campaign within the next iteration of the Agile Development Approach. Due to a possible lack of trust and/or competition issues within the IT and heritage community, the next iteration will further consider building more personal face-to-face relationships with the greater community through, for example, conferences or visits to departments and institutions.

\section{REFERENCES}

Alzaghoul, A. F. (2013). The Implication of the Learning Theories on Implementing E-Learning Courses. The Research Bulletin of Jordan , II, 28-29.

Bak, G. (2012). Building the Crowd: Archives as Social Networks. High-Tech Heritage: Changing Visions, Media and Rationales in the 21st Century Conference, UMASS Amherst, May 2-4, 2012 (p. Abstract n.pag). Amherst, USA: University of Manitoba, Canada.

Bonk, C., \& Reynolds, T. (1997). Learner-centered Web instructions for higher-order thinking, teamwork, and apprenticeship. In B. Khan, Web-Based Instruction (pp. 167178). Englewood Cliffs, NJ, USA: Educational Technology Publications.

Breslin, J. G., Decker, S., Harth, A., \& Bojars, U. (2006). SIOC: an approach to connect web-based communities. International Journal of Web Based Communities , 2 (2), 133-140.

Bruckman, A. (2004). Co-Evolution of Technological Design and Pedagogy in an Online Learning Community. In S. Barab, \& R. Kling, Desiging for Virtual Communities in the Service of Learning (pp. 239-255). Cambridge, UK: Cambridge University Press.

Campos, M. (2004). A Constructivist Method for the Analysis of Networked Congnitive Communication and theAssessment of Collaborative Learning and Knowledge-Building. CiteSeer $X$ $6 M$, n.pag. 
Chippindale, C., \& Taçon, P. S. (1998). The Archaeology of Rock-Art. Cambridge: Cambridge University Press.

Christen, K. (2013). Mukurtu - 1200+ pieces of content and growing . Retrieved 01 2013, 10, from Long Road : http://www.kimberlychristen. com/?p=201

Cunningham, W., \& Leuf, B. (2001). The Wiki Way: Quick Collaboration on the Web. Addison-Wesley.

Department of the Environment. (2011). State of the Environment Report. Department of Sustainability, Environment, Water, Population and Communities, Australian State of the Environment Committee . Australian Government.

Du, J., Durrington, V. A., \& Mathews, J. G. (2007). Online Collaborative Discussions: Myth of Valuable Learning Tool. MERLOT Journal of Online Learning and Teaching , 3 (2), 94104.

European Commission Information Society and Media. (2011, 4). COAR Repositories. (N. N. Candela, Ed.) Retrieved 2 24, 2015, from DL.org: Coordination Action on Digital Library Interoperability, Best Practices and Modelling Foundations : https://www.coar-repositories.org/files/D3-2b-Digital-LibraryReference-Model.pdf

Forte, A., \& Bruckman, A. (2007). Constructing Text: Wiki as a toolkit for (collaborative?) learning. WikiSym '07. Proceedings of the 2007 international symposium on Wikis (pp. 31-42). New York, NY, USA: ACM.

Gafni, R., \& Geri, N. (2010). The Value of Collaborative ELearning: Compulsary versus Optional Online Forum Assignments. Interdisciplinary Journal of E-Learning and Learning Objects. IJELLO special series of Chais Conference 2012 best papers , 6, 335-343.

Gavrilis, D., Ioannides, M., \& Theofanous, E. (2015). Cultural Heritage Content Re-Use: An Aggregators's Point of View. ISPRS Ann. Photogramm. Remote Sens. Spatial Inf. Sci. II5/W3, 83-87, pp. 83-87. ISPRS.

Girvan, C., \& Savage, T. (2010). Identifying an appropriate pedagogy for virtual worlds: A Communal Constructivism case study. Computers \& Education, 55 (1), 342-349.

Gousios, G., Vasilescu, B., Serebrenik, A., \& Zaidman, A. (2014). Lean GHTorrent: GitHub data on demand. MSR 2014 Proceedings of the 11th Working Conference on Mining Software Repositories (pp. 384-387 ). New York, USA: ACM.

ICOM/CIDOC Document Standards Group, CIDOC CRM Special Interest Group. (2015, 01 27). Definition of the CIDOC Conceptual Reference Model. (P. D. Le Boef, Ed.) Retrieved 01 28, 2015, from http://www.cidoccrm.org/official_release_cidoc.html\#CIDOCCRM6.0

Khattab, M. A., Fouad, Y., \& Rawash, O. A. (2009). Proposed Protocol to Solve Discovering Hidden Web Hosts Problem. IJCSNS International Journal of Computer Science and Network Security, 9 (8), 247-254.

Leask, M., \& Younie, S. (2001). Communal constructivist theory: information and communications technology pedagogy and internationalisation of the curriculum. Journal of Information Technology for Teacher Education , 10 (1-2), 117134.
Pack, M. J., \& Goicoechea, J. (2000). Sociocultural and Constructivist Theories of Learning: Ontology, Not just Epistemology. Educational Psychologist, 35 (4), 227-241.

Papert, S., \& Harel, I. (1991). Situating Constructionism. In Constructionism (pp. 193-206). Ablex Publishing Corporation.

Piaget, J. (1967). Biologie et connaissance. Gallimard: collection Idées, n.pag.

Rahmanian, B., \& Davis, J. (2013). Crowdsourcing, Cognitive Load, and User Interface Design. 24th Australasian Conference on Information Systems, 4-6 Dec 2013, (pp. 1-12). Melbourne.

Raiciulescu, L. (2012). Ancient Times, Modern Means: Curating Archaeological Collections in the Digital Age. HighTech Heritage: Changing Visions and Rationales in the 21st Century, UMass (p. Abstract n.pag.). Amherst, USA: Metropolitan Museum.

Roschelle, J. (1992). Learning by Collaborating: Convergent Conceptual Change. Journal of the Learning Sciences , 2 (3), 235-276.

Sabelli, N. (2008). Constructionism: A New Opportunity for Elementary Science Education. DRL Division of Research on Learning in Formal and Informal Settings , 193-206.

Stuedahl, D., \& Smordal, O. (2012). Matters of Durability, Maintainance and Continuity in Digital Intangible Heritage. High-Tech Heritage: Changing Visions, Media and Rationales in the 21st Century, UMass (p. Abstract n.pag.). Amherst, USA: University of Oslo.

Swartz, A. (2006, 09 14). Making More Wikipedias. Retrieved 08 12, 2015, from Raw Thought: http://www.aaronsw.com/weblog/morewikipedias

Tangney, B., FitzGibbon, A., Savage, T., Mehan, S., \& Holmes, B. (2001). Communal Constructivism: Students constructing learning for as well as with others. Society for Information Technology \& Teacher Education International Conference, 2001 in . Norfolk, VA, USA: Association for the Advancement of Computing in Education (AACE).

W3Techs. (2015). Usage of Content Management Systems for Websites. Retrieved 08 11, 2015, from W3Techs Web Technology Surveys: http://w3techs.com/technologies/overview/content_management /all

Weilenmann, A. (2013). Instagram at the museum: communicating the museum experience through social photo sharing. CHI '13 Proceedings of the SIGCHI Conference on Human Factors in Computing Systems , 1843-1852.

Wightman, D. (2010). Crowdsourcing Human-Based Computation. NordiCHI 2010, October 16-20, 2010 (pp. 551560). Reykjavik, Iceland: ACM.

Wood, D. (1998). How Children Think and Learn (Vol. 2nd edition). Oxford: Blackwell Publishers Ltd.

Yueh, H.-P., Huang, J.-Y., \& Chang, C. (2015). Exploring Factors Affecting Students' Continued Wiki Use For Indiviusal and Collaborative Learning: An Extended Utaut Perspective. Australasian Journal of Education Technology, 31 (1), n.pag.

Revised 4 May 16 